\title{
Multi-temporal high-resolution polarimetric L-band SAR observation of a wine-producing landscape
}

\author{
A. Burini, F. Del Frate, A. Minchella, G. Schiavon, D. Solimini \\ UniversitàTorVergata,DISP, Roma, Italy (schiavon@uniroma2.it) \\ R. Bianchi, L. Fusco \\ ESA/ESRIN, Frascati, Italy (Remo.Bianchi@esa.int) \\ R. Horn \\ DLR, Wessling, Germany (ralf.horn@dlr.de)
}

\begin{abstract}
In continuation of the BACCHUS project, aimed at establishing a reference high quality geographic information system for vineyards, an airborne SAR survey has been carried out in fall 2005 in the Frascati area, near Rome (Italy) to demonstrate the potential of airborne radar remote sensing in vineyard characterization.

This contribution reports on the polarimetric L-band and dual polarization C-band SAR data acquisition campaign supported by ESA and carried out on two dates in October 2005 (the first during the grape harvest and the other after the vintage completion).
\end{abstract}

\section{INTRODUCTION}

Many theoretical and experimental studies have demonstrated the sensitivity of microwave backscattering to vegetation characteristics and efforts are under way to exploit SAR observations operationally. The radar sensitivity to vegetation originates from the different volumes of biological matter which affect the wave-plant-soil interaction mechanisms. Backscattering is thus affected by the type of plant and by its development stage. Indeed, in their development cycles, crops like maize, sunflower, colza, or alfalfa, considerably change the number, dimensions and shapes of the scattering elements, thus modifying their radar return. Geometrical features of cultivations, including distances between rows and between single plants, as well as row orientation and terrain slope with respect to the observing direction, can also dramatically change the features of the imaged areas. Given the number of variables which affect the radar images, sophisticated tools are required to satisfactorily classify wine producing areas, which are usually complex, fragmented and hilly. Moreover, to perform their task, the discriminating algorithms must be fed with a maximum number of measured pieces of information, hence polarimetric radar measurements are needed, possibly in an interferometric configuration.

The sensitivity of radar returns to the vegetal matter hints at the feasibility of measuring vegetation biomass and, possibly, fruit biomass. Although strong limitations are still present, the possibility of measuring the above ground forest stand volume [1]-[3] and of monitoring the development of crops like wheat or rice [4]-[6], has been demonstrated. The situation is different when the plants have a stable woody structure which is only slightly modified by the developing fruits. In this case, monitoring the fruit biomass by radar observations is made difficult by the small variations of backscattering with respect to a strong, almost saturated (at least at C-band) background. Measurements on vineyards are even more difficult, given the high number of poles and metallic wires supporting the runners. Subtle measurements are then required through suitable processing of the SAR images aiming at reducing the interfering effects of the stable structures, of the meteorological and climatological conditions, of plant phenology and cultivation practices. In an attempt to gain some insight on these issues, a preliminary experiment was carried out in cooperation with ESA/ESRIN to investigate on the sensitivity of ERS SAR measurements to developing grapes [7]. An increase of the normalized sigma-nought during the summer months and its drop in September/October were consistently observed and attributed to the development and subsequent harvest of the grapes.

\section{THE “BACCHUS - DOC” EXPERIMENT}

Within the BACCHUS project [8] a high quality geographic information system for the Frascati wine region was developed. Thanks to the availability of this reference system, and on the basis of the previously introduced experiences, the Earth Observation Programme of the European Space Agency included an airborne campaign, named "BACCHUS-DOC" [9], devised to demonstrate the potential of radar remote sensing in land applications and, in particular, in vineyard monitoring.

The main scientific objectives of the campaign are:

- Investigation on the polarimetric radar potential in vineyards inventory and characterization.

- Assessment of the polarimetric radar potential in monitoring bio-geo-physical parameters, like soil moisture and grape biomass, which can be useful in farming practices.

The experiment took place in the fall of 2005. The DLR ESAR Synthetic Aperture Radar system onboard a Dornier DO 228 aircraft flew over part of the Frascati wine producing area on 5 October, when grapes were still present, and on 25 October, after vintage [10]. The study area was imaged at high spatial resolution $(\sim 2 \mathrm{~m})$ at C-band at $v v$ and $v h$ polarizations and at L-band in a fully polarimetric mode. The area of interest was covered by two strips of size $3 \mathrm{~km} \mathrm{x} 7 \mathrm{~km}$ each, overlapping each other by about $500 \mathrm{~m}$; corner reflectors were 
placed, one in each strip, as ground control points for georeferencing (Fig. 1). The flight paths were almost parallel to the ERS 2 and ENVISAT ground tracks, to allow comparison with archived data. The imaged surface is shown in Fig. 2, in the frame of the Colli Albani area and of the urban outskirts of Rome.

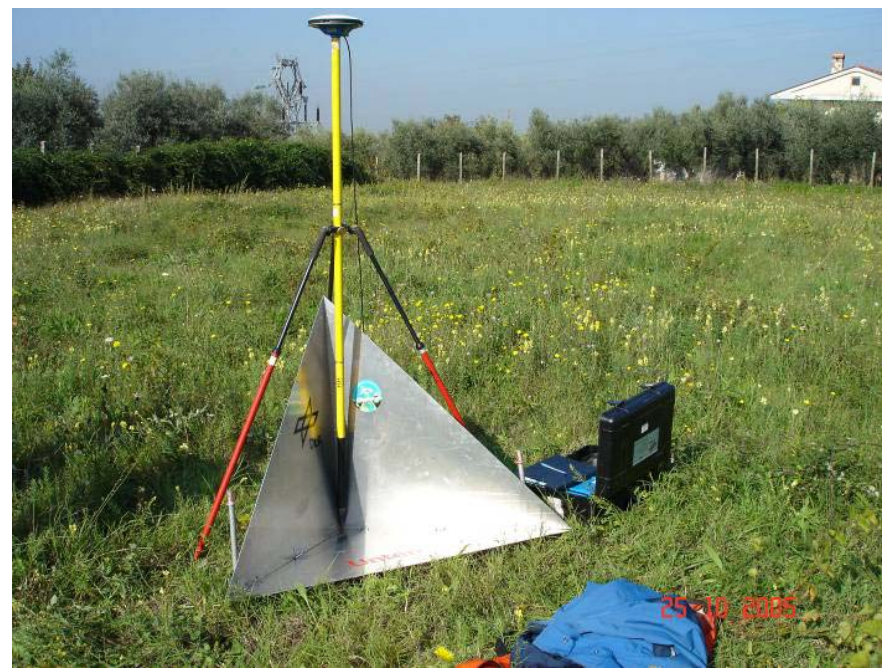

Fig 1. Corner reflectors were deployed for georeferencing.
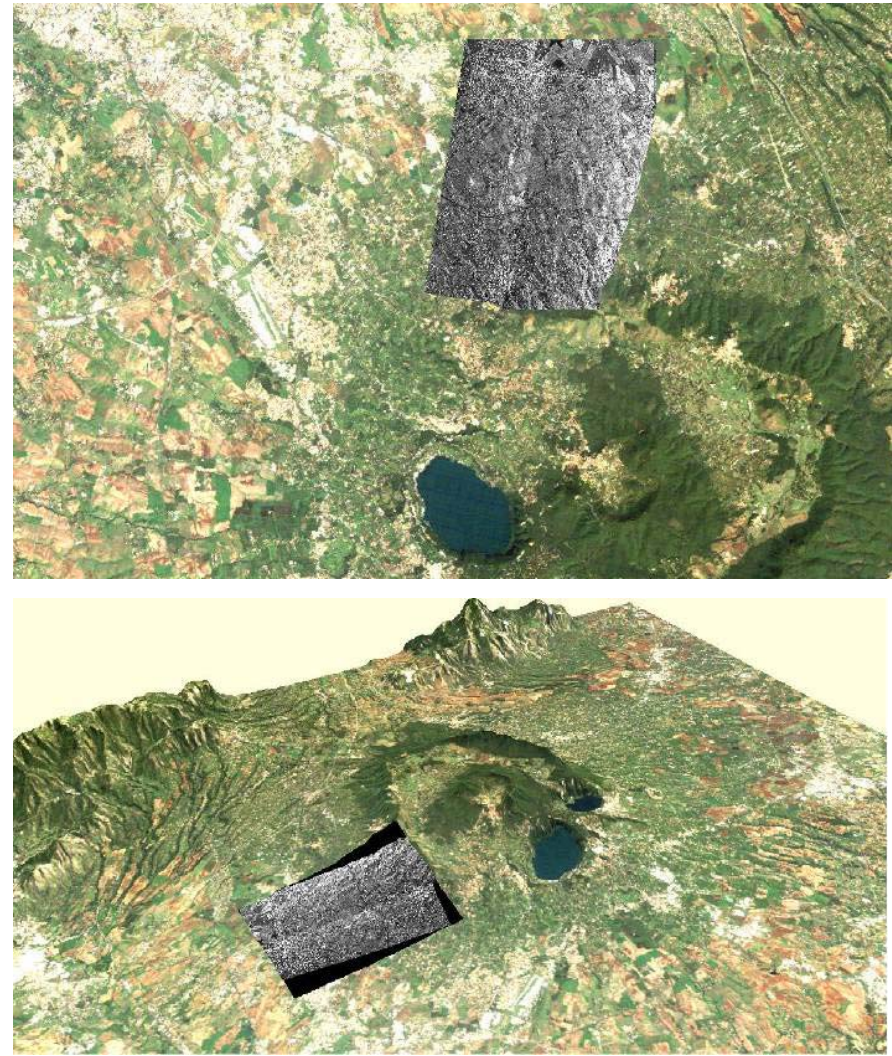

Fig 2. The Frascati imaged test site (in gray) within the wide Castelli Romani area and the SE outskirts of Rome, Italy.

The SAR acquisitions were accompanied by contemporary ground measurements on the vineyards. An extensive survey identified the general conditions of vegetation and of the terrain in a wide area of the Frascati wine production. Intensive measurements were carried out on relatively flat parcels imaged at two different incidence angles and belonging to the Pietra Porzia estate [11]. Two areas were selected, one with vine rows almost parallel to the flight ground track, the other nearly orthogonal. Several parameters were measured, including row and vine spacing, leaf height distribution and dimensions, number of leaves per unit area, height distribution and dimension of grapes (Fig.3), number of grapes per unit area, average grape weight, dimensions of trunks and stalks, geometry of supporting poles and wires, roughness and moisture of the terrain, weed height. The selected areas lie within the overlapping region of the two strips, hence are imaged at two different incidence angles, i.e., at about $27^{\circ}$ and around $53^{\circ}$.

Each SAR image has been radiometrically calibrated using also a DEM to evaluate the local incidence angle and a layer stack has been created for easier data handling. The L-band RGB composite images of the central part of the study area are reported in Figs. 4 and 5.

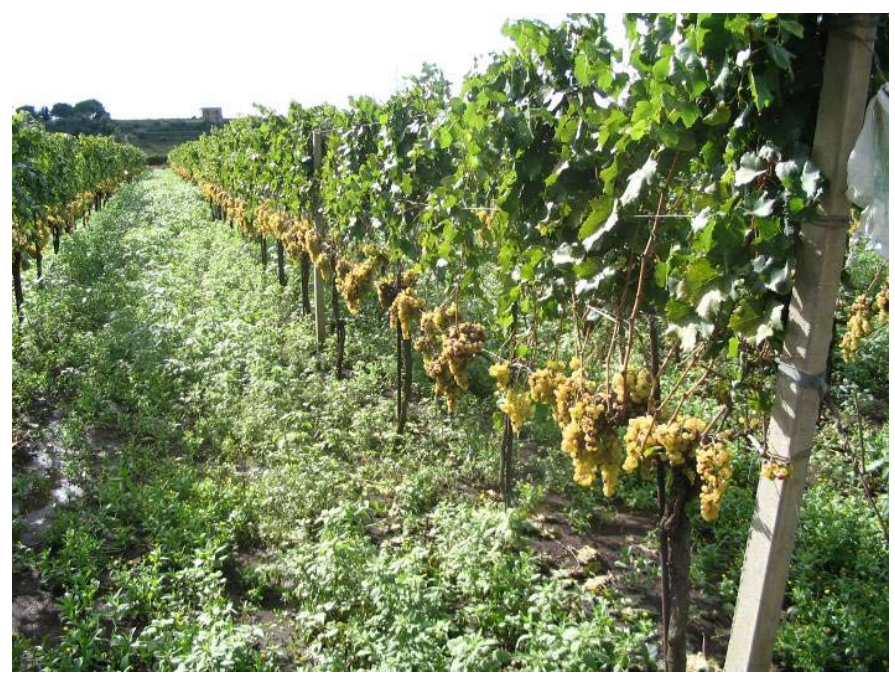

Fig 3. Parameters of plants, grapes and supporting structures were measured.

A variety of radar responses result from the combination of the backscatter at the various polarizations. A first inspection links some of the striking image features to the type of vine cultivation, and in particular, to the orientation of the vineyard rows, nearly parallel or orthogonal to the flight line, or to the tent-like set ups. Fine variations of the polarimetric backscattering are also apparent within a same field. A quantitative comparison between the two images, which is essential towards the assessment of the SAR potential in monitoring the grape biomass, is made difficult by the different meteorological conditions affecting the two flights. Indeed, frequent rain showers occurred on the $5^{\text {th }}$ of October, adding up to several previous rainy days. The soil was soaked and even puddles were present (Fig. 6). Water drops were lying on the leaves, films of water wrapped the supporting structures and the wood of the trunks was wet. The climatic situation was different on occasion of the second flight, which took place after several dry days which had considerably reduced the soil 
moisture content, on a sunny afternoon, when leaves, trunks and supporting structures were dry. Given the substantially different environmental conditions, several assumptions on which the previous investigation [7] was based are not valid anymore. A new approach is needed to attack the challenging issue of estimating the biomass of grapes by radar.

\section{ACKNOWLEDGMENT}

The support by ESA/ESRIN, also through the BACCHUS Project, is gratefully acknowledged.

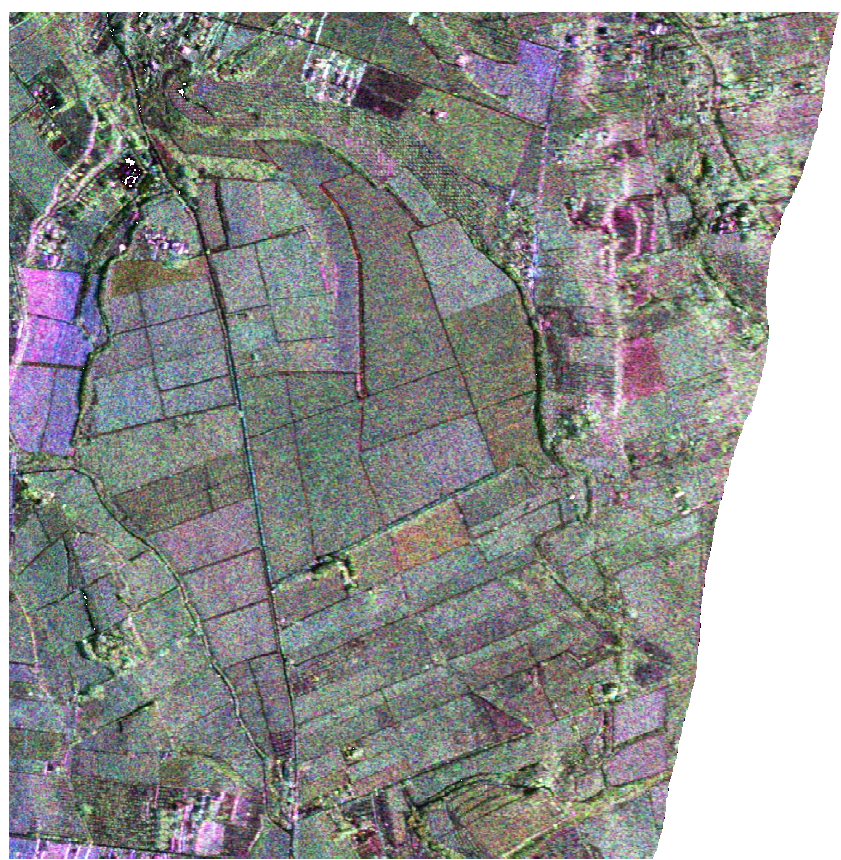

Fig 4. Part of the vineyards in the Frascati area imaged at L-band, vv, hv, hh polarizations (RGB) on 5 October 2005.

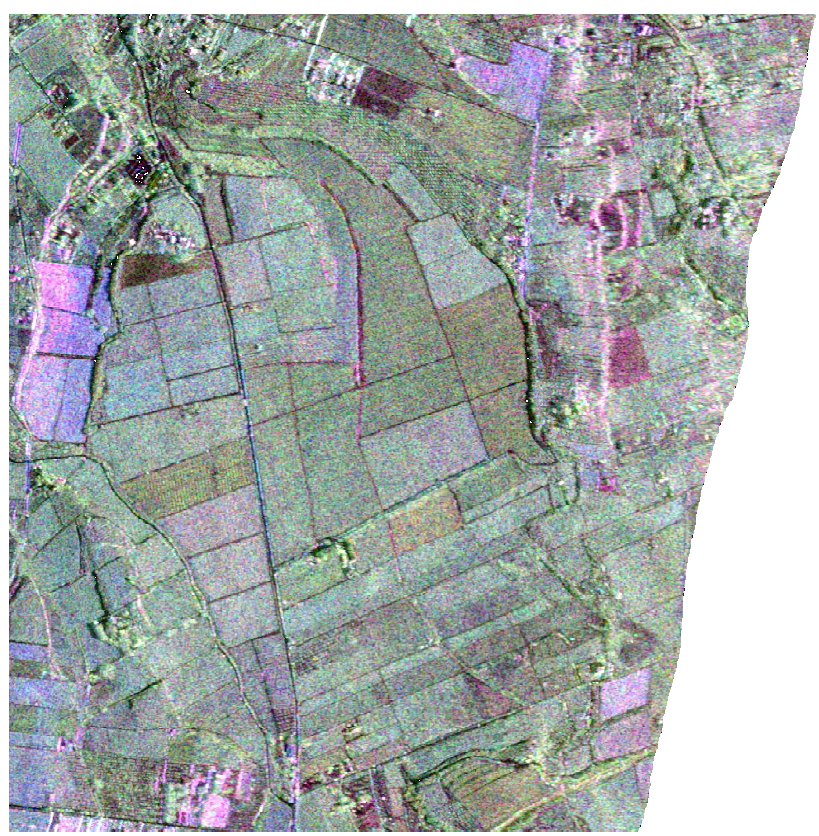

Fig 5. Part of the vineyards in the Frascati area imaged at L-band, vv, hv, hh polarizations (RGB) on 25 October 2005.

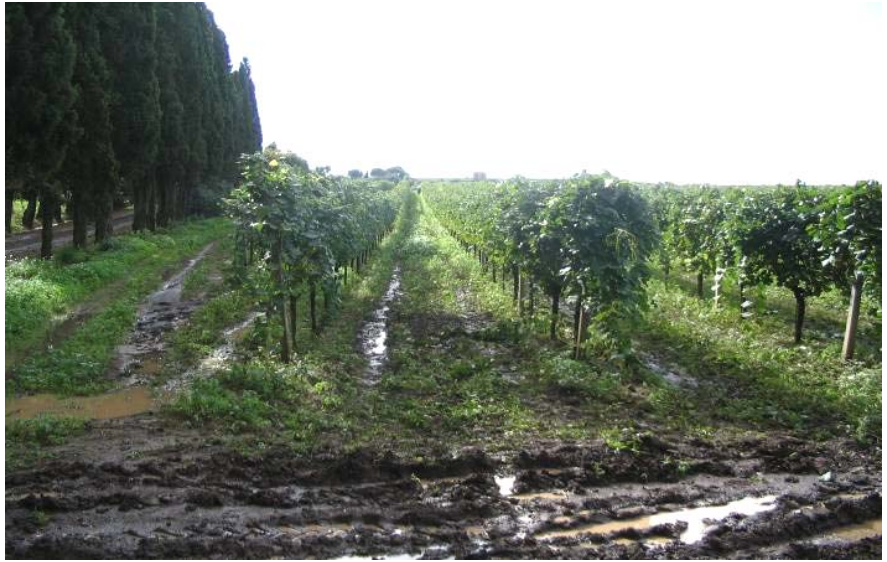

Fig 6. Wet soil conditions on 5 October 2005.

\section{REFERENCES}

[1] M.C. Dobson, F.T. Ulaby, T. Le Toan, A. Beaudoin, E.S. Kasischke, and N.L. Christensen, Jr., "Dependence of radar backscatter on coniferous forest biomass", IEEE Trans. Geosci. Remote Sens., vol. 30, pp. 643-659, 1992.

[2] K.P. Papathanassiou, I. Hajnsek, T. Mette, and A. Moreira, "Model based forest parameter estimation from single baseline Pol-in-SAR data: the Fichtelgebirge test case", Proc. POLinSAR Workshop on Applications of SAR Polarimetry and Polarimetric Interferometry (http://earth.esa.int/polinsar), ESA-ESRIN Frascati, Italy, 14-16 Jan., 2003.

[3] F. Del Frate and D. Solimini, "On neural network algorithms for retrieving forest biomass from SAR data", IEEE Trans. Geosci. Remote Sens., vol. 42, pp. 24-34, 2004.

[4] F. Ribbes and T. Le Toan, "Rice field mapping and monitoring with RADARSAT data", Int. J. Remote Sens., vol. 20, pp. 745-765, 1999.

[5] F. Del Frate, P. Ferrazzoli, L. Guerriero, T. Strozzi, U. Wegmuller, G. Cookmartin, and S. Quegan, "Wheat cycle monitoring using radar data and a neural network trained by a model", IEEE Trans. Geosci. Remote Sens., vol. 42, pp. 35-44, 2004.

[6] I. Hajnsek, and S.R. Cloude, "Pol-InSAR for Agricultural Vegetation Parameter Estimation", Proc. IGARSS'04, Anchorage, U.S.A., vol. II, pp. 1224 - 1227, 2004.

[7] A. Burini, A. Minchella, D. Solimini, "SAR in agriculture: Sensitivity of backscattering to grapes", Proc. IGARSS'05, Seoul, Korea, 2005.

[8] The Bacchus project web site: http://www.bacchusproject.com

[9] R. Horn, "BACCHUS-DOC Radar and Optical Campaign, Experiment Plan", ESRIN/19188/05/I-LG, Sept. 2005.

[10] R. Horn, "BACCHUS-DOC Radar and OpticalCampaign, Data Acquisition Report", ESRIN/19188/05/I-LG, Dec. 2005.

[11] http://www.tenutadipietraporzia.it/tenutaporzia/index.html 